\title{
DIE WORDING VAN 'N SUID-AFRIKAANSE KERKHISTORIESE BIBLIOGRAFIE: 'N HISTORIESE EN BIBLIOGRAFIESE OORSIG
}

J W Hofmeyr

\section{ABSTRACT}

THE MAKING OF A SOUTH AFRICAN CHURCH HISTORICAL BIBLIOGRAPHY: AN HISTORICAL AND BIBLIOGRAPHIC SURVEY.

The compilation of the History of the church in Southern Africa: a select bibliography of published material (compiled and edited by $\mathrm{J} W$ Hofmeyr and $\mathrm{K}$ E Cross) is discussed especially in historical perspective. The prime purpose of this article is to provide information both for the continuation of the project itself and to give for various purposes the outsider an insight into the compilation of a bibliography of this nature.

\section{Inleiding}

Naas argiewe en biblioteke as navorsinginstellinge is bibliografieë een van die mees basiese navorsingsapparate met die oog op die beoefening van die kerkhistoriese wetenskap. Juis te midde van 'n byna ongelooflike wêreldwye inligtingsontploffing het die koördinasie en toeganklik maak ook van wetenskaplike inligting van des te groter belang geword.

Met die verskyning in 1986 en 1988 van die eerste twee volumes van History of the church in Southern Africa: a select bibliography of published material " saamgestel en geredigeer deur J W Hofmeyr en K E Cross en onderskeidelik 809 en 129 bladsye in omvang, het kerkhistoriese navorsing in Suid-Afrika moontlik 'n nuwe era betree. Vir die eerste keer in die geskiedenis van die kerkhistoriese wetenskap in Suid-Afrika is ' $n$ verteenwoordigende en omvattende versameling van bibliografiese inligting oor haas alle gepubliseerde materiaal (tydskrifartikels uitgesluit) oor die periode strekkende van die vroegste vestigingsjare tot 1985 in twee enkele volumes saamgevat.

Hierdie artikel het eerstens ten doel om vir die buitestaander 'n beeld te gee op die wordingsgeskiedenis van 'n bibliografie wat spesifiek gerig is op die Suid-Afrikaanse kerkgeskiedenis. ${ }^{21}$ Tweedens kan die terugkyk op die vyftien jaar sedert daar met hierdie projek in 1975 begin is, ' $n$ waardevolle bestekopname bied wat op sy beurt weer tot die verbetering en verfyning van die verdere projek kan dien. Derdens kan hierdie oorsig vir diegene wat soortgelyke projekte op verwante studieterreine wil aanpak, tot moontlike nut en voordeel wees. Op die langer termyn kan ten slotte 'n oorsig soos in hierdie artikel aangebied as ' $n$ nuttige agtergrond dien vir 'n omvattende beoordeling van die bydrae en belangrikheid van hierdie projek. 


\section{Historiese oorsig}

Hierdie bibliografiese projek staan nie alleen te midde van wêreldwye ontwikkelinge op die terrein van kerkhistoriese bibliografieë nie. Enkele standaardwerke op hierdie terrein sluit byvoorbeeld die volgende in: W P C Knuttel, Nederlandsche bibliographie van kerkgeschiedenis (Amsterdam, 1889); L D Petit, H Ruys, Repertorium van boeken en tijdschriftartikelen op het gebied van de geschiedenis van Nederland (Leiden, 1943); P G Mode. Source book and bibliographical guide for American church history (Menasha, Wisconsin 1921) en N R Burr, J W Smith, A L Jamison, A critical bibliography of religion in America (Princeton, 1961).

Hiernaas staan hierdie bibliografiese projek ook nie los van die navorsings- en publikasie-aktiwiteite van een van die samestellers daarvan, te wete skrywer van hierdie artikel nie. Dit het, alhoewel dit nie oorspronklik eksplisiet so deur hom beplan is nie, almeer deel begin word van 'n breër doel om uiteindelik 'n nuwe perspektief op die SuidAfrikaanse kerkgeskiedenis te help realiseer. So 'n nuwe perspektief behels nie 'n revisionistiese of radikale visie nie, maar wel in soverre as wat dit moontlik is, ' $n$ hervertolking van die Suid-Afrikaanse kerkgeskiedenis langs nie-apologetiese en nie-ideologiese weë. Die uiteindelike doel is om hetsy in spanverband of alleen 'n hele aantal navorsingsresultate juis met die oog hierop die lig te laat sien. Die twee bibliografiese volumes hier onder bespreking is dan die eerste vrugte van hierdie breë navorsingsprogram. Ander korttermynprojekte in hierdie program is twee verdere volumes in hierdie bibliografiese reeks. Die een sal 'n supplement tot die bestaande twee bibliografieë van gepubliseerde monografieë en boeke wees, en dit sal hopelik teen 1992 die lig sien. Die ander sal 'n bibliografie van tydskrifartikels wees en die publikasiedatum daarvoor is waarskynlik laat in 1991. Verdere korttermynprojekte is ' $n$ gidsboek tot kerkhistoriese inligting en bronne vir gebruik veral deur die kerkhistoriese navorser, wat hopelik nog in 1990 sal verskyn, asook 'n dokumente- en bronnepublikasie oor die Suid-Afrikaanse kerkgeskiedenis soortgelyk aan die bekende bronnepublikasie van $\mathrm{H}$ Bettenson, Documents of the Christian Church ${ }^{3)}$ wat moontlik teen 1991 sal kan verskyn. Publikasies wat vir die medium- en langer termyn beplan word is ' $n$ kerkhistoriese woordeboek van Suid-Afrika, 'n Suid-Afrikaanse kerkhistoriese atlas, 'n geillustreerde beeldboek oor die Suid-Afrikaanse kerkgeskiedenis en uiteindelik ook 'n nuwe geskiedenis van die Christendom in Suid-Afrika.

Lank reeds is die behoefte aan 'n projek soos dié en die publikasie van 'n kerkhistoriese bibliografie gevoel. Interessant is dit byvoorbeeld dat in ' $n$ verslag van die Argiefkommissie wat voor die Algemene Sinode van die Nederduitse Gereformeerde Kerk in 1962 gedien het, die wenslikheid van'n bibliografie oor die Suid-Afrikaanse kerkgeskiedenis uitgespreek is. 
Dit was uiteindelik die gesamentlike inisiatief van W S Vorster, hoof van die Instituut vir Teologiese Navorsing (wat tans nog steeds toesig hou oor die projek) en J A Stoop, voormalige hoof van die Departement Kerkgeskiedenis van die Universiteit van Suid-Afrika, wat in 1975 gelei het tot die permanente vestiging van hierdie projek by Unisa. $\mathrm{J}$ A Stoop het tot in 1982 as projekleier daarvan opgetree. Ek het in 1978 by hierdie projek betrokke geraak. In 1980 het ek mede-projekleier geword en sedert 1982 projekleier.

Sonder die volgehoue en toegewyde arbeid van 'n hele aantal navorsingsassistente in die loop van vyftien jaar, waarvan sommige ook inligtingkundig baie goed toegerus was vir die taak, sou hierdie projek waarskynlik nooit 'n werklikheid geword het nie. Hulle was in chronologiese orde P van der Walt (1974-1976), P E S Smith (19751976), J L J Smit (1977-1978), C Landman (1979-1980), M Vermeulen (1981-1988), K E Cross (1981-1988), J Rykheer (1988 tot hede) en M Nel (1989 tot hede).

Die samewerking tussen diegene wat die projek geïnisieer, bestuur en gelei het en diegene wat as navorsingsassistente opgetree het, was deurgaans van hoë gehalte. Voortdurende betrokkenheid, skakeling en die fisiese medewerking tussen die verskillende vennote het uiteindelik 'n goeie resultaat tot gevolg gehad. Dit het verder ook duidelik geblyk dat 'n gesonde wisselwerking tussen die nodige kerkhistoriese vakkennis enersyds, en bibliografiese en inligtingkundige kennis andersyds, 'n noodsaaklikheid is vir die suksesvolle afhandeling van so 'n onderneming. Honderde besluite met betrekking tot die in- of uitsluiting van items, die klassifikasie en redigering daarvan en die opstel van indekse is in die loop van die projek geneem. Juis vanweë die goeie begrip en wisselwerking tussen die vennote was besluitneming wel 'n tydrowende, maar nooit 'n krisisvolle onderneming nie. Uiteindelik dien hierdie projek as 'n sigbare bewys van goeie samewerking en die nodige spanwerk tussen ' $n$ navorsingsinstituut, ' $n$ akademiese departement en inligtingkundiges, in hierdie geval almal verbonde aan die Universiteit van Suid-Afrika.

Die oorspronklike doel met hierdie projek was om 'n omvattende bibliografie van die kerkgeskiedenis van die hele Afrika aan te pak. Dit het egter al hoe meer 'n onmoontlike opgaaf geblyk te wees. Ongelukkig het ook dit naas enkele ander faktore soos die wydheid van die chronologiese periode en 'n gebrek aan praktiese ervaring daartoe bygedra dat die uiteindelike publikasie van die eerste volumes vir 'n geruime tyd vertraag is.

In plaas daarvan om die projek uiteindelik net na 'n enkele land af te skaal, is besluit om dit eerder tot een van die substreke in Afrika, naamlik Suidelike Afrika te beperk. 'n Belangrike les wat hieruit geleer is, is dat eerder ' $n$ te klein as ' $n$ te groot geografiese gebied afgebaken moet word. 
Tans behels hierdie projek dus 'n geselekteerde bibliografie van gepubliseerde materiaal (uitgesonderd tydskrifartikels) oor die Christelike kerk suid van die Kunene en Zambesi vanaf die vroegste vestigingsjare tot op datum.

Verskeie belangrike tendense met betrekking tot die kerkhistoriese wetenskap in Suid-Afrika is in die proses van die samestelling van hierdie bibliografie bespeur. Allereers is die feit nogmaals herbevestig dat die Suid-Afrikaanse kerkhistoriografie gestrem word deur ' $n$ baie spesifieke apologetiese en partikularistiese neiging. Dit het dikwels tot gevolg dat kerkhistorici kerkgeskiedenis vanuit een of ander eksklusiewe gesigspunt benader. Verder is 'n redelike groot persentasie van hierdie materiaal populêr en daar is dus ' $n$ besondere leemte aan wetenskaplik verantwoorde kerkgeskiedskrywing.

Tweedens dui die bibliografie aan die een kant 'n oorvloed van gepubliseerde materiaal oor bepaalde kerke en onderwerpe aan en aan die ander kant 'n gebrek aan aandag weer vir bepaalde ander kerke en temas. Dit kan dikwels toegeskryf word aan 'n gebrek aan historiese bewussyn of tradisie in ' $n$ bepaalde kerk. Daar is dus ' $n$ opvallende wanbalans ten opsigte van kerkhistoriese materiaal oor verskillende kerke.

Derdens blyk dit ook dat die onderskeiding wat grootliks om praktiese redes in die eerste twee volumes tussen kerke en sendinggenootskappe getref is, besig is om te vervaag. Dit het voorheen heelwat probleme in die klassifikasieproses tot gevolg gehad. Daar is dus besluit dat dit nie meer langer teoreties of prakties verantwoordbaar is nie en dat hierdie kategorieë voortaan saamgegroepeer sal word.

Ten slotte moet ook nog gestel word dat slegs 'n beperkte aantal van die versamelde items van 'n aanvoeling vir die kerk in die breë spreek. Veel kan dus in Suid-Afrika nog gedoen word wat betref die kaleidoskopiese of ekumeniese perspektief op die kerkgeskiedenis.

\section{Bibliografiese oorsig}

Vervolgens sal aandag gegee word aan 'n aantal bibliografiese aspekte. In hierdie verband moet daarop gewys word dat een van die ander hoofsamestellers van hierdie bibliografie, te wete $\mathrm{K} E$ Cross, reeds aan bepaalde bibliografiese riglyne vir die samestelling van hierdie bibliografie aandag gegee het en wel in ' $n$ klein publikasie getitel $A$ guide to editing and standardising items for a bibliography ${ }^{4)}$. Op daardie aspekte sal hier dus nie verder ingegaan word nie.

Die samestelling van hierdie bibliografieë het in sewe verskillende fases uiteengeval. Die eerste fase het ' $n$ breë doelwitstelling behels, dit wil sê wat, hoe en wanneer moet deur wie bereik word. Die tweede fase het die bepaling van die belangrikste bronne en instellinge waaruit materiaal met die oog op die bibliografie opgestel sou word, behels. In 
' $n$ derde fase is die fisiese versameling van die materiaal gedoen en dit was natuurlik die langste proses. 'n Groot verskeidenheid nasionale bibliografieë, gespesialiseerde onderwerpsbibliografieë, akademiese verhandelinge, gepubliseerde kerkgeskiedenisse asook die katalogusse van ' $n$ groot verskeidenheid biblioteke is in hierdie proses geraadpleeg. In ' $n$ vierde fase is die versameling geselekteer en wel primêr op grond van die vraag of ' $n$ bepaalde item in ' $n$ kerkhistoriese bibliografie tuishoort. In ' $n$ vyfde fase is die materiaal in vier rubrieke geklassifiseer $\mathrm{nl}$. algemeen, denominasies, sendinggenootskappe en temas. In ' $n$ sesde fase is die finale bibliografiese redigering van die totale versameling gedoen om dit in ooreenstemming te bring met die Anglo-American Cataloging Rules ${ }^{5}$. Dit is ' $n$ katalogiseringskode wat op 'n wye vlak gebruik word in biblioteekkatalogusse asook in omvattende bibliografieë maar ook met die oog op rekenarisering aangepas kan word. In ' $n$ finale fase is persoons- en onderwerpsindekse opgestel.

Die bibliografieë is tot dusver primêr toegespits op gepubliseerde materiaal wat tydskrifartikels uitgesluit het. Dit het dus hoofsaaklik monografieë, boeke, pamflette en versamelbundels behels. V'erder is akademiese verhandelinge op $\mathrm{M}$ - en D-vlak ook ingesluit. Naas die ooglopende materiaal is ook enkele moontlik ongewone stof ingesluit. Preke is ingesluit in soverre as wat dit kerkhistories belangrik is. Liturgieë, liedboeke, kategismusse en Bybelvertalings is normaalweg nie ingesluit nie, behalwe waar die fokus meer bepaald op die historiese ontwikkeling daarvan was. Kerkordelike materiaal en kerklike regulasies is wel dikwels ingesluit omdat dit aandui hoe kerklike regering in bepaalde kerke gevestig is en ontwikkel het.

Die geografiese fokus van hierdie bibliografie omvat die gebied suid van die Kunene en die Zambesi. Dit sluit dus Suid-Afrika, Botswana, Lesotho, Swaziland, Namibia en Zimbabwe in, maar dit sluit Mosambiek uit, gewoon omdat daar nie soveel direkte kerklike aansluiting tussen Suid-Afrika en Mosambiek is nie.

Ook die afbakening van kerkgeskiedenis as studieveld was eweneens van groot belang. Daar moes naamlik gekies word tussen ' $n$ te breë of ' $n$ te eng definisie van die vakgebied. Tussen enersyds 'n te eng definisie waar bloot gekyk word na die kerk binne sy institusionele grense en andersyds ' $n$ te breë definisie waar omtrent elke moontlike saak tot kerkgeskiedenis gemaak word, is uiteindelik vir 'n middeweg gekies. Oor die algemeen is met die definisie van G. Ebeling gefunksioneer waarvolgens kerkgeskiedenis die geskiedenis van die uitleg van die Woord is maar dan tog wel in die breë sin van die woord. Dit het dus ook te make met die wisselwerking tussen kerk en samelewing.

Alhoewel ook hierdie publikasies nie op absolute volledigheid aanspraak kan maak nie, is tog daarna gestreef om 'n so volledig as moontlike versameling daar te stel. Omdat bewustelik besluit is om 
geen annotasies oftewel waarde- en inhoudsopmerkinge aan die materiaal toe te voeg nie, is daar nie in die versameling by voorbaat keuses gemaak ten opsigte van bruikbare en minder bruikbare materiaal nie. Hierdie keuse is aan die gebruiker self oorgelaat.

Betreffende indekse of registers, is daar van twee aspekte sprake. Die naamindeks sluit persoonlike outeurs, korporatiewe outeurs, konferensies, redakteurs, samestellers van publikasies, die onderwerpe van biografieë en persone aan wie erebundels opgedra is, in. Die onderwerpsindeks is ' $n$ alfabetiese sleutel tot die sistematiese rangskikking van die bibliografie. Dit bied naas die inhoudsopgawe aan die gebruiker die nodige gereedskap om hopelik met sukses 'n bepaalde soektog te voltooi.

\section{Beoordeling van hierdie bibliografieë}

Dat ' $n$ bibliografie, om as geslaagd beskryf te word, aan sekere vereistes moet voldoen, staan soos 'n paal bo water. In hierdie verband het S Tabachnick onlangs 'n baie waardevolle kontrolelys vir die resensente van bibliografieë daargestel wat tegelyk as 'n maatstaf vir 'n bibliografie soos dié een hier onder bespreking, kan dien ${ }^{6}$. Andersyds is ' $n$ belangrike voorlopige toets vir die geslaagdheid van hierdie bibliografie geleë in die reaksie wat dit by resensente ontlok het.

In die ontwikkeling van 'n kontrolelys maak Tabachnick voorsiening vir vyf hoofafdelings. Die eerste hoofafdeling fokus op die gesaghebbendheid van die samestellers asook van die uitgewer. In 'n tweede hoofafdeling word gefokus op die verantwoording van die kant van die samestellers. Daar behoort gevra te word of die samestellers hulle genoegsaam ten opsigte van die vakgebied, die doel en fokus van die bibliografie, die metode wat gevolg is, die bestuur van die projek en die uiteindelike struktuur van die eindproduk verantwoord het.

In 'n derde hoofafdeling word voorsiening gemaak vir die evaluering van die inhoud van ' $n$ bibliografie. Sake wat aan die orde kom, is die geskiktheid, korrektheid, volledigheid, konsekwentheid, uniekheid en waardevolheid van die versameling. In 'n vierde hoofafdeling word gefokus op die geslaagdheid van klassifikasie, styl en indekse in 'n gegewe bibliografie. Vrae oor die geskiktheid, volledigheid en konsekwentheid daarvan moet beantwoord word. In 'n laaste hoofafdeling word gevra na die tegniese en tipografiese afwerking van die inhoud en van die uiteindelike publikasie self. Uiteindelik sal die bibliografie hier onder bespreking aan al die maatstawwe wat hier uitgespel is, getoets moet word.

Die voorlopige reaksie wat hierdie bibliografiese projek uitgelok het, en wel by wyse van ' $n$ aantal resensies, was besonder bemoedigend. ' $n$ Twaalftal resensies is reeds ontvang waarvan twee uit SuidAfrika en die res uit die buiteland, verteenwoordigend van drie ander kontinente. Kommentaar het gewissel van "a classic" tot "a masterful 
survey". Verder is gestel dat dit "(an) essential book(s) on missiology" is en "(it) is the result of careful planning, thorough research and detailed collecting of information; for these reasons it will be an indispensable resource for any library or scholar interested in African church history". 'n Mens sou dus met 'n mate van reg kan beweer dat wat die voorlopige beoordeling van hierdie bibliografie aanbetref, dit ook elders ter wêreld ' $n$ belangrike plek in toekomstige navorsing oor die SuidAfrikaanse kerkhistoriese toneel gaan inneem.

Dit is hier egter nie die primêre waarop gefokus wil word nie. Van groter belang is die punte van kritiek en van daaruit die moontlike riglyne vir die verdere suksesvolle voortsetting van hierdie projek. Volgens sommige resensente is ten spyte van 'n reeds breë definisie van die vakgebied, 'n te eng perspektief gehandhaaf; verder dat daar leemtes ten opsigte van bepaalde kerke bestaan; dat daar enkele kleiner probleme rondom die klassifikasiesisteem en die indekse bestaan, dat geen annotasies tot die bibliografiese materiaal toegevoeg is nie en dat tydskrifartikels ook ingesluit moes gewees het.

\section{Slot}

Wat die pad vorentoe met hierdie bibliografiese reeks betref, is daar enkele aspekte wat ter sprake gebring moet word.

Allereers moet gestel word dat daar wel aandag gegee is aan die pleidooie wat uit resensies geblyk het vir 'n kerkhistoriese bibliografie van tydskrifartikels. Die eersvolgende publikasie in hierdie reeks wat hopelik laat in 1991 sal verskyn, sal juis die eerste volume wees wat tydskrifartikels sal bevat en dit sal die periode 1975-1990 dek. Aangesien materiaal hiervoor soos ook met die voorafgaande bibliografieë op 'n wêreldwye vlak versamel is, is die mate van oorvleueling met die Suid-Afrikaanse Teologiese Bibliografie" (wat slegs tydskrifartikels bevat wat in Suid-Afrika verskyn het) van heel beperkte aard.

'n Volgende belangrike en uitdagende ontwikkeling wat vir hierdie projek in die vooruitsig lê, is die rekenarisering daarvan. Baie en belangrike besluite sal in die verband geneem moet word. Met groot vrug sou daar egter uit die waardevolle lesse wat deur die samestellers van die Suid-Afrikaanse Teologiese Bibliografie te wete C F A Borchardt, J Kilian en W S Vorster geleer is, geput kon word.

Ten slotte sal voortgesette noue skakeling en koördinasie met die samestellers van die Suid-Afrikaanse Teologiese Bibliografie (wat trouens ook'n projek van die Instituut vir Teologiese Navorsing aan die Universiteit van Suid-Afrika is) gehandhaaf moet word om die moontlike potensiaal vir oorvleueling en duplisering tot die minimum te beperk. Huidig is daar egter geen rede tot kommer in hierdie verband nie en hierdie twee projekte dien as wesenlike aanvullings tot mekaar. 
Soos waarskynlik uit die voorgaande blyk, staan hierdie kerkhistoriese onderneming op ' $n$ besondere gesonde grondslag. Daar word gehoop dat die toekomsverwagtinge van hierdie projek tesame met andere hierbo genoem, nie sal beskaam nie en dat dit alles sal dien en bydra tot die verdere uitbou van die kerkhistoriese wetenskap in SuidAfrika.

\section{NOTAS}

1. J W Hofmeyr and K E Cross, History of the church in Southern Africa: a select bibliography of published material (Vol 1 and 2), Pretoria 1986, 1988.

2. Kyk ook J Botha, "Compilation of the RSANB: Retrospective South African National Bibliography", Suid-Afrikaanse Tydskrif vir Biblioteek- en Inligtingkunde. Vol. 53, no.4 (1985), 209-214.

3. H Bettenson, Documents of the Christian Church, Oxford, 1967.

4. $\mathrm{K}$ E Cross, $A$ guide to editing and standardising items for a bibliography, Pretoria 1986.

5. Anglo-American Catalogung Rules $\left(A A C R^{2}\right)$. London ${ }^{2} 1978$.

6. S Tabachnick, "Reviewing printed subject bibliographies: a worksheet", The Journal of Academic Librarianship. Vol. 15, no.5 (1989), 279-284.

7. C F A Borchardt, J Kilian \& W S Vorster, Suid-Afrikaanse Teologiese Bibliografie (Vol. 1 tot 4), Pretoria 1980, 1983, 1988, 1989. 